\title{
EVOLUÇÃO DA SITUAÇÃO SOCIOPROFISSIONAL DOS LICENCIADOS EM GESTÃO E DESENVOLVIMENTO SOCIAL
}

\author{
Paulo Almeida Pereira*
}

Nos últimos anos, o Instituto Universitário de Desenvolvimento e Promoção Social tem-se empenhado em seguir o percurso dos seus licenciados, nomeadamente do curso de Gestão e Desenvolvimento Social.

Apresentam-se resultados de estudos anuais, desde 1998 a 2001, que permitem avaliar a evolução de diversos aspectos relacionados com a situação socioprofissional dos referidos diplomados, como a taxa de desemprego e características do trabalho desempenhado: sector de actividade em que se integra, localização geográfica, nivel de remuneração e tipo de contrato de trabalho, entre outros. A avaliação realizada resulta extremamente positiva.

Apresenta-se também a importância para as funções desempenhadas, reconhecida pelos licenciados, das diferentes áreas científicas da licenciatura e a relevância de diversos factores para a obtenção do emprego.

Procede-se, finalmente, ao estudo das áreas de especialização, preferidas pelos diplomados com intenção de prosseguir os seus estudos, ao nivel de pós-graduação.

Instituto Universitário de Desenvolvimento e Promoção Social - Pólo de Viseu do Centro Regional das Beiras da Universidade Católica Portuguesa 
Palavras-chave: Licenciados em Gestão e Desenvolvimento Social, situação socioprofissional, estatística.

\section{INTRODUÇÃO}

Desde 1986, a Universidade Católica Portuguesa tem vindo a ministrar a licenciatura em Gestão e Desenvolvimento Social (GDS), no âmbito de uma das suas unidades científico-pedagógicas implementadas na cidade de Viseu - Instituto Universitário de Desenvolvimento e Promoção Social. Ao longo de todos estes anos, os seus licenciados têm atingido notoriedade no mercado de trabalho regional e nacional, com alguns casos de bastante sucesso.

Tem sido uma preocupação, dos órgãos desta escola, o acompanhamento da evolução da situação socioprofissional dos licenciados em GDS, através de estudos realizados periodicamente, que consistem na recolha de dados amostrais. Anualmente, no decorrer dos últimos quatro anos, tem sido aplicado um questionário por correio, aos licenciados em GDS, durante os três anos anteriores à recolha de dados, acompanhado de um envelope endereçado para resposta, com taxa paga. As amostras foram recolhidas por este método, que não garante a sua aleatoriedade.

\section{Quadro I LICENCIADOS INQUIRIDOS}

\begin{tabular}{cc}
\hline Ano de aplicação do questionário & População estudada - licenciados em: \\
\hline 1998 & $1995 / 1996$ a $1997 / 1998$ \\
1999 & $1996 / 1997$ a $1998 / 1999$ \\
2000 & $1997 / 1998$ a $1999 / 2000$ \\
2001 & $1997 / 1998$ a $2000 / 2001$ \\
\hline
\end{tabular}

O processo de amostragem tem como objectivo avaliar vários aspectos considerados relevantes, sobre os licenciados em GDS, parecendo-nos importante, neste ano, a realização de uma retrospectiva sobre a evolução dos dados recolhidos.

A representatividade das amostras recolhidas tem mantido um valor aproximadamente constante, ao longo dos quatro anos, sendo medida pelo conjunto dos elementos da população que responderam ao 
questionário, com valores sempre próximos dos $44 \%$, em cada um dos momentos de aplicação do estudo, devendo-se a taxa de não-respostas ao facto da base de dados de residências dos licenciados estar desactualizada, responsável por aproximadamente 5\% das não-respostas e à não resposta à solicitação.

Para simplificar a análise dos resultados, grande parte destes serão apresentados em frequências relativamente ao número de respostas recolhidas, validamente expressas, sobre cada questão.

\section{CARACTERIZAÇÃO DOS LICENCIADOS}

No questionário aplicado, foram recolhidas as mais diversas informações sobre os licenciados em GDS, que passarão a ser apresentadas. Note-se que, nos últimos anos, o questionário foi enriquecido, pelo que existem aspectos cuja análise só será referida para os anos mais recentes. $O$ ano de aplicação do questionário será considerado o ano de referência para caracterização dos resultados.

A maioria dos licenciados em GDS é do sexo feminino, diferença que se acentua para o último ano, em que três quartos dos diplomados são deste sexo.

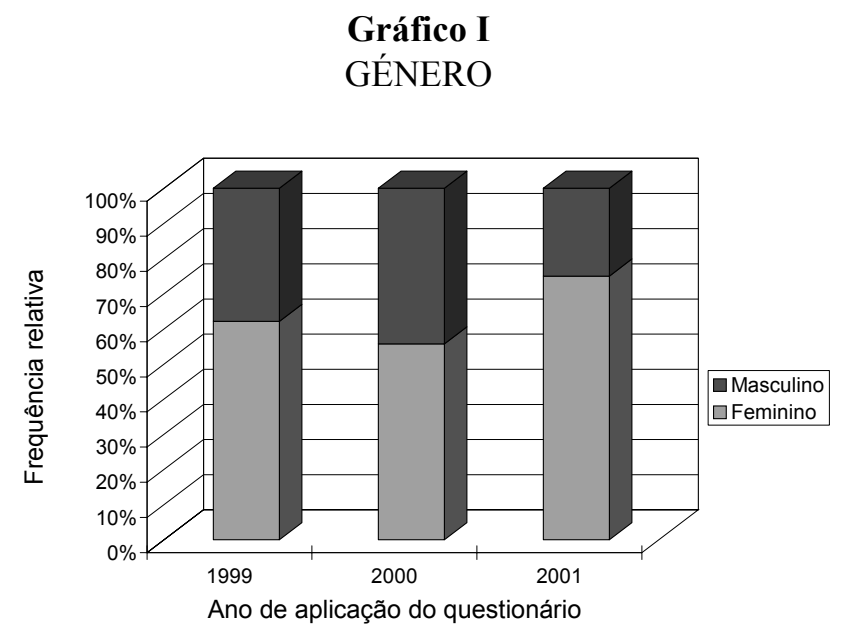

\section{Quadro II}

IDADE DOS LICENCIADOS 


\begin{tabular}{ccc}
\hline Ano & Média das idades & Desvio padrão das idades \\
\hline 1999 & 27,55 & 3,74 \\
2000 & 27,66 & 2,78 \\
2001 & 28,53 & 3,51 \\
\hline
\end{tabular}

A média das idades dos licenciados, para cada ano, refere-se aos diplomados dos últimos três anos, pelo que não pode ser confundida com a idade com que terminaram o curso. Nota-se um aumento nas médias de idades, para anos mais recentes. Em todas as situações, mais de $60 \%$ dos licenciados apresentam idade inferior à média.

\section{SITUAÇÃO SOCIOPROFISSIONAL}

$\mathrm{O}$ primeiro e principal indicador analisado reside na taxa de desemprego que, de valores próximos de 13\% em 1998, baixou significativamente para cerca de 3\% em 2001. É de realçar a existência de dois tipos de desempregados, aqueles que nunca trabalharam e os que estão momentaneamente desempregados. Apenas nos dois primeiros anos se observa a ocorrência da primeira categoria de desemprego. Nas restantes situações, ocorre um período de transição entre empregos, cuja razão, nalguns casos esporádicos, se deve à realização de estudos de pósgraduação.

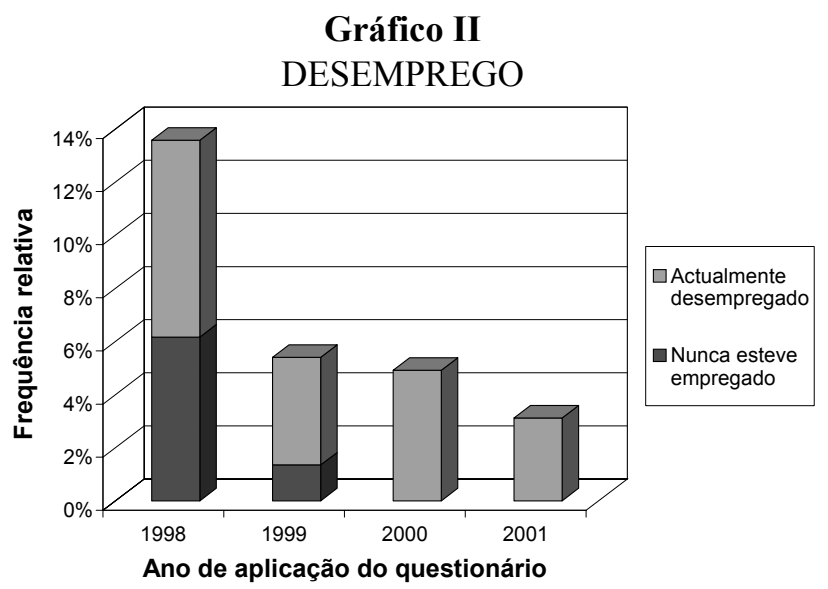

O tempo de espera entre a conclusão da licenciatura e a concretização do primeiro emprego tem vindo a diminuir nos anos mais recentes: em 
2001, a maioria dos alunos já estava empregada antes de concluir os seus estudos. O número de licenciados empregados antes de terminar o curso ou logo no primeiro mês, após a conclusão do mesmo, aumentou de valores de 60\% em 1998 (já significativos) para perto de 80\% em 2001. Já aqueles que demoram mais de seis meses a concretizar o objectivo do primeiro emprego, passaram de valores ao redor de $14 \%$, nos três primeiros anos do estudo, para $6 \%$ em 2001. Existe uma, cada vez mais, rápida integração no mercado de trabalho.

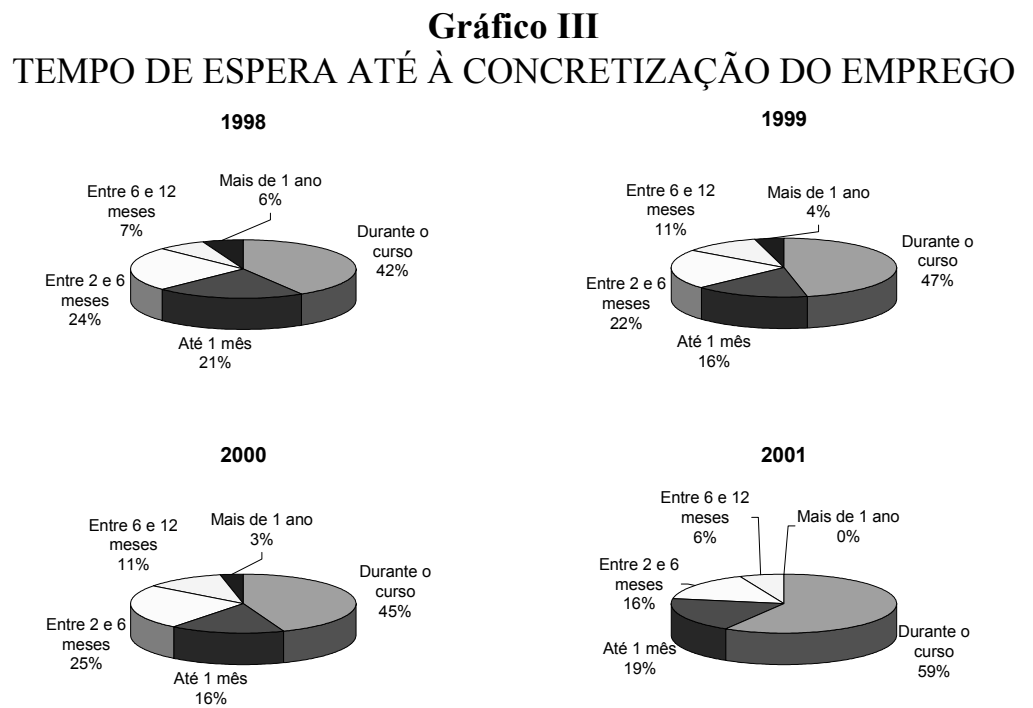

A rotação no mercado de trabalho apresenta valores relativamente baixos: ao longo dos anos, apenas cerca de $40 \%$ dos licenciados não se mantêm no primeiro emprego que conseguiram. Este aspecto é, certamente, influenciado pelo facto das amostras incluírem apenas licenciados num período de três anos antes da recolha de dados.

Um dado extremamente relevante, que contribui positivamente para a reduzida taxa de desemprego observada nos últimos anos, é a relação evidenciada entre o estágio curricular, com a duração de quatro meses, que integra o quinto ano do plano de estudos da licenciatura. Sobre este ponto apenas se encontram disponíveis dados para os anos de 2000 e 2001 , indicando que cerca de $40 \%$ e $50 \%$ dos empregos, respectivamente, estão directamente relacionados com o estágio curricular. Este é, certamente, um ponto forte da licenciatura, que promove o contacto dos 
recém-licenciados com o mercado de trabalho e, como se pode comprovar pela relevância observada, a possibilidade de demonstrar as mais-valias resultantes da integração de um diplomado em GDS na organização em que tem oportunidade de estagiar. 


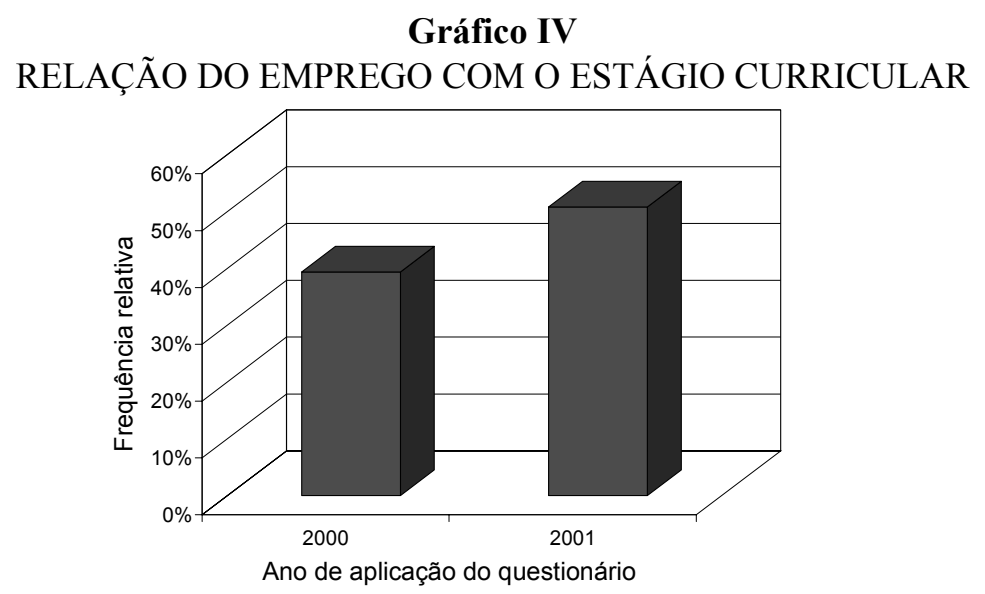

A licenciatura em GDS é um curso de banda larga, que prepara os seus licenciados para actuar em diversos campos de actividade, principalmente no sector terciário, mas também no sector secundário. Verifica-se que a banca tem absorvido alguns dos diplomados, tendo, no entanto, vindo a perder o seu peso relativo nos anos mais recentes, devido, seguramente, à política de redução de efectivos do sector bancário. A percentagem de licenciados integrados na indústria mantém, ao longo dos anos, valores entre os $15 \%$ e $20 \%$, sendo, em 2000 e 2001, o sector onde a empregabilidade de licenciados em GDS é superior, por troca com a banca, que dominava o mercado de trabalho nos anos anteriores. Os restantes serviços não se encontram desagregados para o ano de 1998, apenas para os anos seguintes. Esta desagregação permite evidenciar a presença na área comercial, no sector administrativo e na função pública, o aumento relativo de licenciados colocados na área social ou associações de desenvolvimento em 2001 e a presença, sempre significativa, de diplomados a exercerem funções ligadas à contabilidade ou fiscalidade. Surgem também situações, mais esporádicas, ligadas ao ensino e seguros.

Um dado importante para caracterizar o emprego reside na análise da segurança associada à actividade desenvolvida, para o que se pode utilizar o indicador relativo ao tipo de contrato com a entidade empregadora. Nos três anos estudados, os licenciados com contratos de trabalho efectivos passou de valores à volta de $55 \%$ para $65 \%$; por outro lado, os contratos a prazo diminuíram de $32 \%$ para $22 \%$. Cerca de $10 \%$ dos licenciados aproveitam a possibilidade de estágios profissionais, 
promovidos em parceria com o Instituto de Emprego e Formação Profissional. Observam-se ainda valores residuais de diplomados colaborando sob a forma de prestação de serviços e colocados como sócios ou gerentes.

\section{Gráfico V}

SECTOR DE ACTIVIDADE
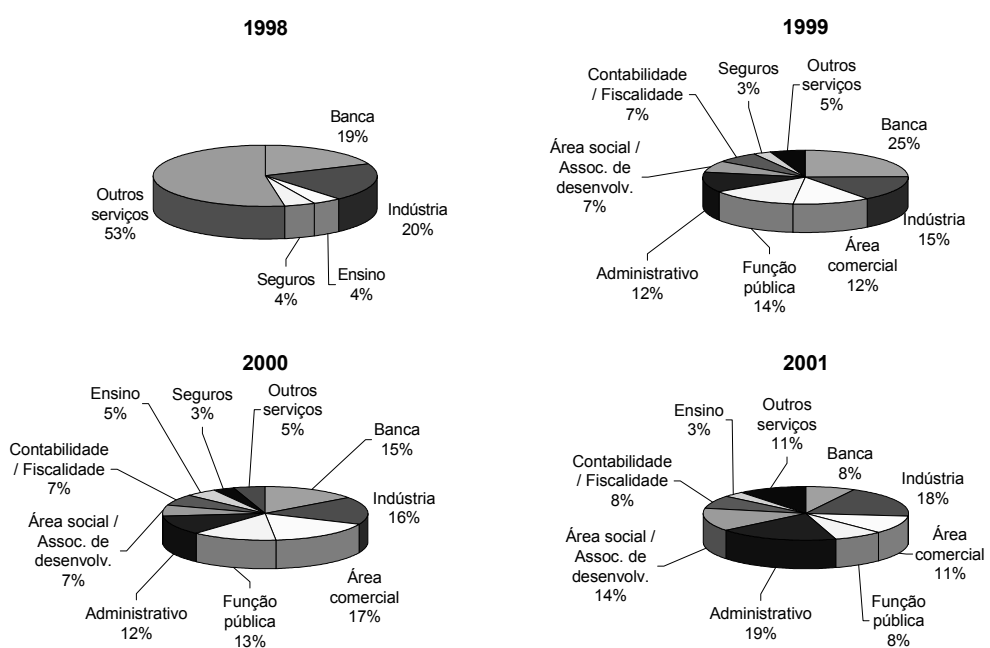

Gráfico VI

TIPO DE CONTRATO DE TRABALHO

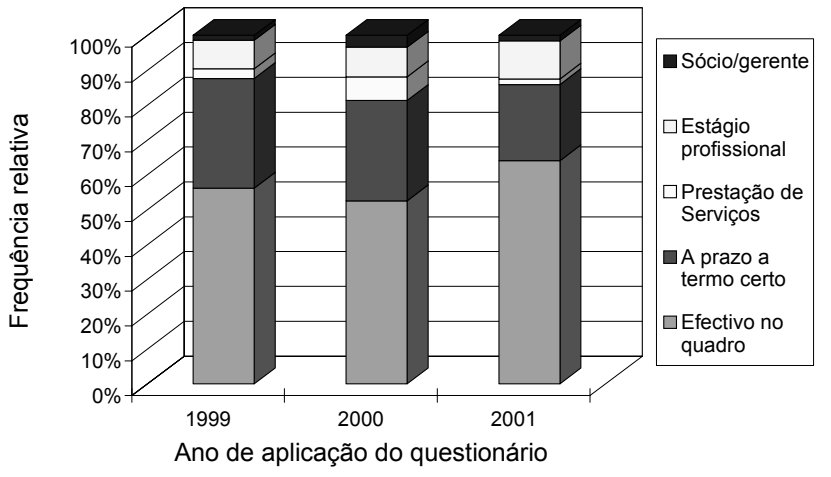


As remunerações ilíquidas mensais têm vindo a aumentar acima da taxa de inflação observada, como se pode observar no Quadro III, que apresenta os seus valores médios para os três anos analisados. Esse aumento deve-se à diminuição dos licenciados em escalões de salário inferiores a 150 contos, tendo aumentado as frequências relativas dos licenciados com vencimentos superiores, particularmente aqueles com salários superiores a 250 contos.

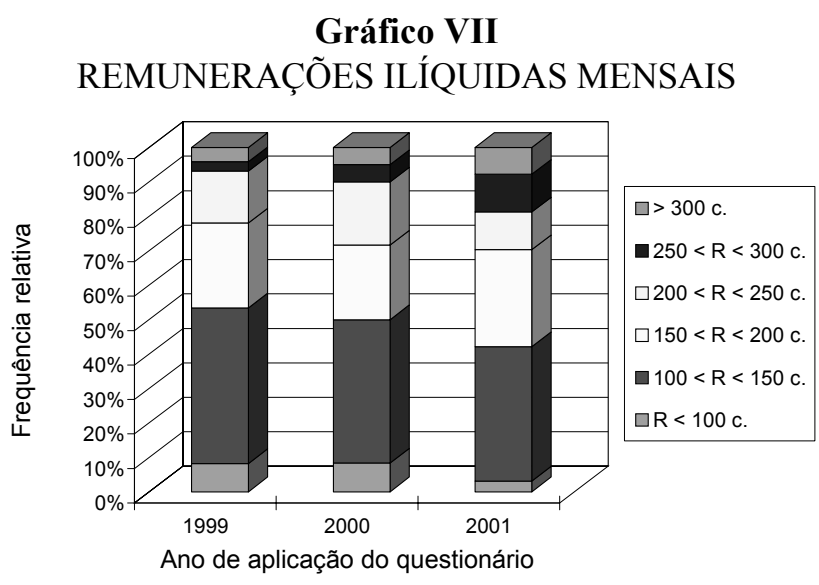

\begin{tabular}{cc}
\multicolumn{2}{c}{$\begin{array}{c}\text { Quadro III } \\
\text { REMUNERAÇÃO MÉDIA }\end{array}$} \\
\hline Ano & Média das remunerações (contos) \\
\hline 1999 & 155,5 \\
2000 & 162,5 \\
2001 & 180,1 \\
\hline
\end{tabular}

Os licenciados em GDS distribuem-se preferencialmente pelo concelho de Viseu (mais de 50\%) e por outros concelhos do respectivo distrito. Apenas valores residuais, na ordem dos 20\%, na sua globalidade, se observam para outros distritos, sendo os mais representativos Coimbra e Aveiro, aparecendo ainda Guarda, Porto, Lisboa, Vila Real e Braga, por esta ordem, com casos pontuais de empregabilidade da população em estudo. 


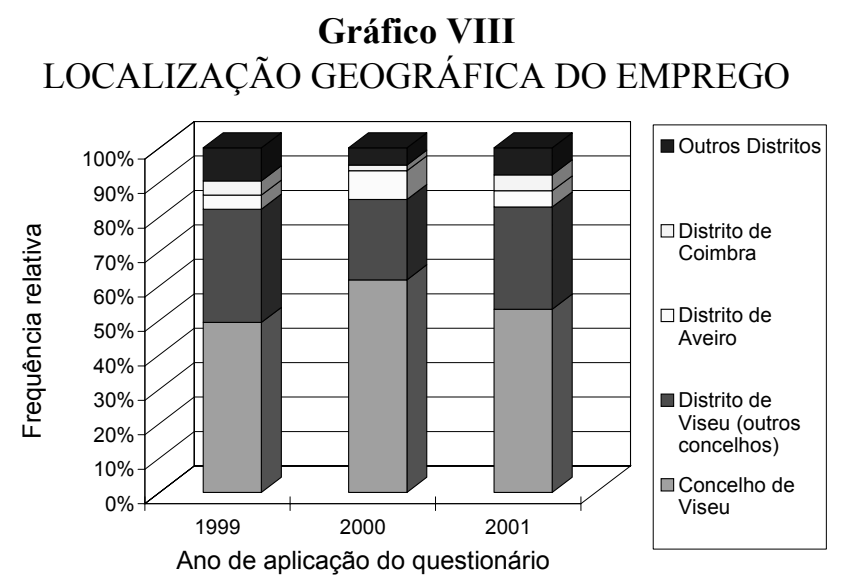

\section{IMPORTÂNCIA DAS ÁREA CIENTÍFICAS DO CURSO}

Considerou-se relevante aprofundar a sensibilidade dos licenciados, relativamente à importância das áreas científicas assimiladas no decorrer da licenciatura, para as funções que desempenham na sua actividade profissional. Com este objectivo, aplicou-se uma escala de Lickert, de um a cinco, cujos resultados médios estão ilustrados pelo gráfico seguinte.

Com excepção da área de Direito, em 1999, de um modo geral, a importância média atribuída a cada uma das áreas científicas tem vindo a diminuir, sendo no entanto considerada positiva, em função da escala definida. As áreas consideradas mais importantes são a Gestão Geral, Finanças, Contabilidade e Fiscalidade e Sistemas de Informação; logo de seguida, apresentam-se as áreas de Marketing e Economia; com importância ligeiramente inferior, são referidas as áreas de Operações, Métodos Quantitativos e Ciências Sociais; finalmente, com uma importância percebida como ainda menor, está a área de Direito. Este escalonamento da importância atribuída a cada uma das áreas do curso está, seguramente, relacionado com as exigências do mercado do trabalho e com as funções desempenhadas, pelos licenciados em GDS, nos sectores de actividade com maior taxa de empregabilidade. 


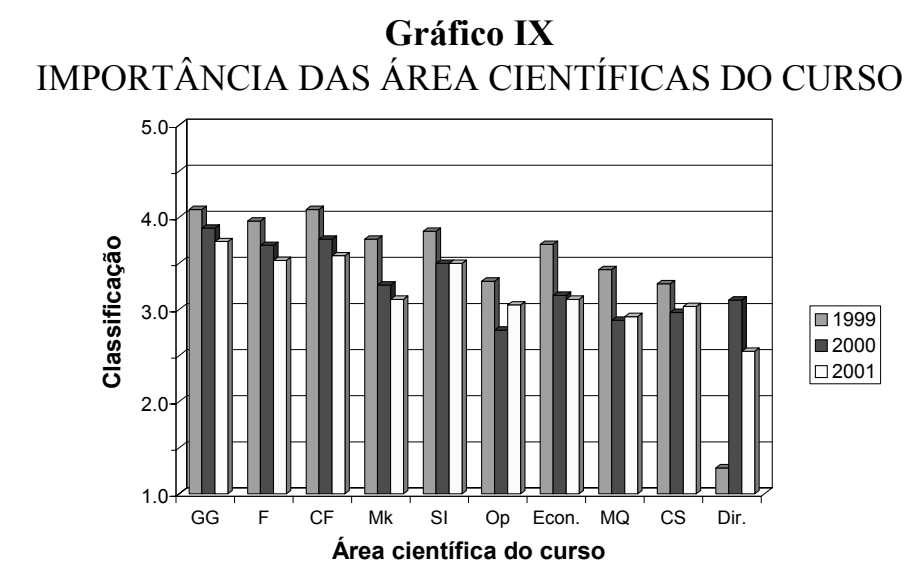

GG - Gestão Geral; F - Finanças; CF - Contabilidade e Fiscalidade; Mk - Marketing; SI Sistemas de Informação; Op - Operações; Econ. - Economia; MQ - Métodos Quantitativos; CS - Ciências Sociais; Dir. - Direito.

\section{FACTORES RELEVANTES PARA A OBTENÇÃO DE EMPREGO}

Tal como no ponto anterior, aplicou-se uma escala de Lickert, idêntica, para averiguar a importância atribuída pelos licenciados, a vários factores, para a obtenção de emprego.

Sucede aqui a mesma situação que anteriomente, uma vez que, de modo geral, a importância média atribuída aos diversos factores diminui para os anos mais recentes. Todos os factores são percebidos como tendo uma importância positiva, com excepção da média da licenciatura, de acordo com a escala definida.

Os factores considerados mais importantes são a autoconfiança e boa apresentação e os conhecimentos científicos aprendidos no decorrer do curso; logo de seguida surgem a própria licenciatura, o seu estágio curricular, o nível de remuneração proposto pela entidade empregadora e os conhecimentos pessoais no mercado de trabalho. Ainda com relevância, mas ligeiramente inferior, surgem as outras áreas de formação e formação profissional, a localização geográfica do emprego e a pesquisa de ofertas de emprego

Deve salientar-se a maior importância atribuída a factores relacionados com a própria licenciatura. 


\section{Gráfico X}

\section{IMPORTÂNCIA PARA A OBTENÇÃO DE EMPREGO}

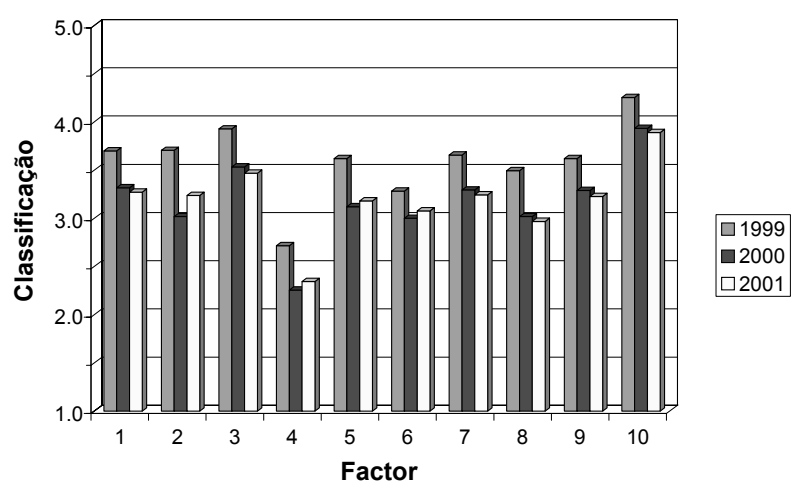

1 - Licenciatura em GDS; 2 - Estágio curricular da licenciatura; 3 - Conhecimentos científicos aprendidos no curso; 4 - Média da licenciatura; 5 - Outras áreas de formação e formação profissional; 6 - Localização geográfica do emprego; 7 - Nível de remuneração; 8 - Pesquisa de ofertas de emprego; 9 - Conhecimentos pessoais no mercado de emprego; 10 - Autoconfiança e boa apresentação

\section{ESTUDOS DE PÓS-GRADUAÇÃO}

Os licenciados que frequentam estudos de pós-graduação apresentam um peso relativo bastante diminuto, desde 4\% em 1999 até 2\% em 2001.

\section{Gráfico XI \\ INTENÇÃO DE FREQUENTAR ESTUDOS DE PÓS-GRADUAÇÃO}

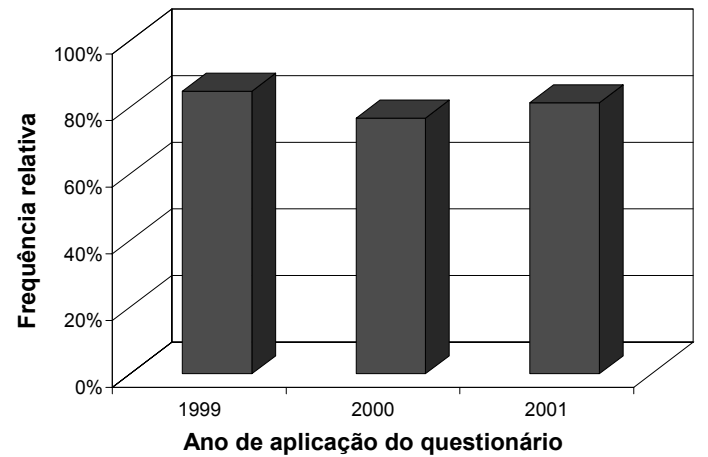


No entanto, esta situação não é indicativa de não terem intenção de o vir a fazer, ocorrendo, talvez, pela pequena oferta existente, a este nível, nas zonas geográficas em que estão integrados. Esta afirmação justificase pelo facto de cerca de $80 \%$ dos licenciados referirem a intenção de vir a frequentar estudos, a este nível, se tal lhes for possibilitado.

Conhecendo esta intenção, torna-se premente saber quais as áreas científicas em que esta apetência é superior. Deu-se a possibilidade, a cada licenciado, com a intenção de efectuar estudos de pós-graduação, de referir, no máximo, três áreas de especialização preferidas. Os resultados desta questão estão ilustrados no gráfico seguinte.

Os valores apresentam algumas flutuações, ao longo dos anos. Pode, no entanto, notar-se que a área mais referida é a da Contabilidade e Fiscalidade. Com um nível de referências imediatamente inferior, surgem os Recursos Humanos e o Marketing, logo seguidos pela Gestão Geral e as Finanças. Onde a apetência por especialização parece ser inferior, é nas áreas dos Sistemas de Informação, Economia, Métodos Quantitativos e Ciências Sociais. O escalonamento da preferências pelas áreas de especialização está, de certo modo, relacionado com a importância atribuída às áreas científicas do curso para as funções que desempenham na sua actividade profissional, embora tal não suceda de forma completamente linear.

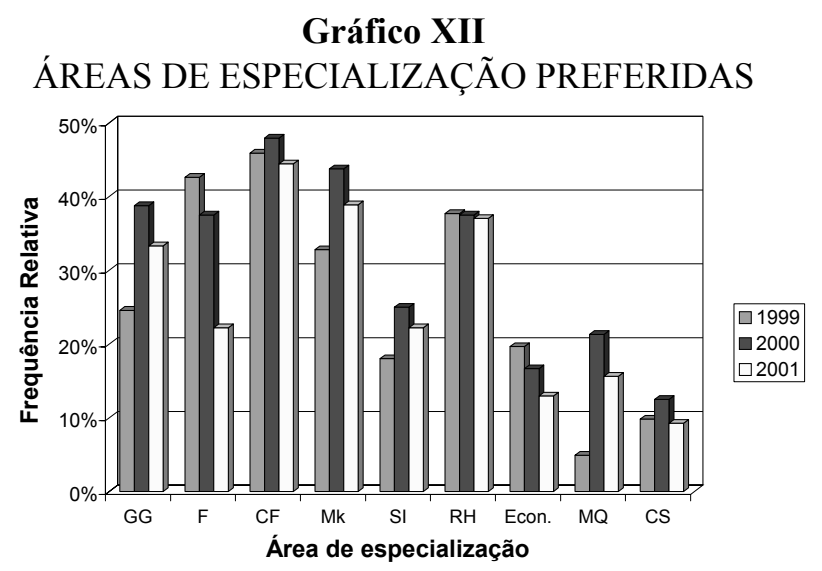

GG - Gestão Geral; F - Finanças; CF - Contabilidade e Fiscalidade; Mk - Marketing; SI Sistemas de Informação; RH - Recursos Humanos; Econ. - Economia; MQ - Métodos Quantitativos; CS - Ciências Sociais. 


\section{CONCLUSÃO}

O Instituto Universitário de Desenvolvimento e Promoção Social temse empenhado, nos últimos anos, em seguir o percurso dos seus licenciados. É importante, além de assegurar uma formação científica e pedagógica adequada a uma licenciatura, verificar a utilização que dela é feita, pelos diplomados. Da análise efectuada, a resposta a esta questão afigura-se-nos extremamente positiva.

A taxa de desemprego dos licenciados tem vindo a diminuir substancialmente, verificando-se, no último ano, valores residuais. $\mathrm{O}$ mercado regional, a quem é dirigida a formação ministrada, tem absorvido os titulares do curso de Gestão e Desenvolvimento Social, com uma apetência crescente, uma vez que os tempos de espera entre a conclusão da licenciatura e a concretização do primeiro emprego têm vindo a diminuir. As remunerações dos licenciados têm aumentado e a importância atribuída pelos diplomados à sua licenciatura é significativa. No entanto, a contribuição da Universidade para a formação dos seus licenciados pode não ficar pela licenciatura, uma vez que eles demonstram uma grande apetência pela continuação dos estudos, ao nível da pós-graduação.

Neste trabalho, foram apenas aplicadas técnicas de estatística descritiva, com o objectivo de ilustrar, de forma simples, a situação socioprofissional dos diplomados, pela Universidade Católica Portuguesa, em Gestão e Desenvolvimento Social. 